\title{
CardNutri: Um software de planejamento de cardápios nutricionais semanais para alimentação escolar aplicando inteligência artificial
}

\author{
CardNutri: software of weekly menus nutritional planning for scholar \\ feeding applying artificial intelligence
}

\section{CardNutri: una desarrollo de menús de software nutricional semanal para la alimentación escolar aplicación de la inteligencia artificial}

\author{
Rafaela Priscila Cruz Moreira | rafapcmor@gmail.com \\ Centro Federal de Educação Tecnológica de Minas Gerais. Belo Horizonte, Brasil. \\ Flávio Vinícius Cruzeiro Martins | flaviocruzeiro@decom.cefetmg.br \\ Centro Federal de Educação Tecnológica de Minas Gerais. Belo Horizonte, Brasil. \\ Elizabeth Fialho Wanner | efwanner@decom.cefetmg.br \\ Centro Federal de Educação Tecnológica de Minas Gerais. Belo Horizonte, Brasil.
}

\section{Resumo}

O objetivo deste artigo é apresentar e avaliar um software que utiliza técnicas de Inteligência Artificial para elaborar, automaticamente e de forma rápida, cardápios nutricionais semanais para a Alimentação Escolar, atendendo às necessidades nutricionais diárias dos alunos e, simultaneamente, minimizando o custo total do cardápio. Esses cardápios satisfazem as referências nutricionais do Programa Nacional de Alimentação Escolar (PNAE) de acordo com a faixa etária, variedade, harmonia das preparações e um valor máximo a ser pago por refeição. O tempo de resposta para essa elaboração não ultrapassa cinco minutos. Contudo, o nutricionista precisa escolher o cardápio que melhor lhe atende, pois a ferramenta fornece um conjunto de cardápios eficientes. Assim, o sistema contribui para a elaboração de cardápios nutritivos e baratos, além de facilitar o trabalho do nutricionista que despende de muito tempo para essa tarefa, uma vez que ele necessita de exercer outras funções de sua responsabilidade.

Palavras-chave: Inteligência Artificial; tecnologia de alimentos; informática em saúde pública; planejamento de cardápio; Alimentação Escolar; software. 


\begin{abstract}
The aim of this paper is to present and evaluate a software that uses Artificial Intelligence techniques to design, automatically and quickly, weekly nutritional menus for School Feeding, meeting the daily nutritional needs of students and simultaneously minimizing the total cost of the menu. These menus meet the nutritional references the National School Feeding Programme (PNAE) according to age, variety, the harmony of preparations and a maximum amount to be paid per meal. The response time for this preparation does not exceed five minutes. However, the nutritionist must choose the menu that suits you best, because the tool provides a set of efficient menus. Thus, the system contributes to the development of nutritious and cheap menus, in addition to facilitating nutritionist work spends much time for this task, since it needs to perform other duties of responsibility.
\end{abstract}

Keywords: Artificial Intelligence; food technology; public health informatics; menu planning; School Feeding; software.

\title{
Resumen
}

El objetivo de este trabajo es presentar y evaluar un software que utiliza técnicas de Inteligencia Artificial para elaborar, de forma automática y rápida, menús nutricionales semanales para alimentación escolar, con el objetivo de satisfacer las necesidades nutricionales diarias de los alumnos y al mismo tiempo reducir al mínimo el costo total del menú. Estos menús siguen las recomendaciones nutricionales del Programa Nacional de Alimentación Escolar (PNAE) de acuerdo al grupo de edad, variedad y armonía de las preparaciones, y costo máximo por comida. El tiempo de respuesta para esta preparación no debe ser superior a cinco minutos. No obstante, el especialista en nutrición debe elegir el menú que más le convenga, ya que la herramienta proporciona un conjunto de menús eficientes. De este modo, el sistema contribuye a la confección de menús nutritivos y baratos, además de facilitar el trabajo del nutricionista, que invierte mucho tiempo en esa tarea, y que tiene que llevar a cabo otras funciones de su responsabilidad.

Palabras clave: Inteligencia Artificial; tecnología de alimentos; informática en salud pública; planificación de menú; Alimentación Escolar; software.

Contribuição dos autores: os autores são responsáveis pelo texto.

Declaração de conflito de interesses: não há.

Fontes de financiamento: Centro Federal de Educação Tecnológica de Minas Gerais, Capes, Fapemig e CNPq.

Considerações éticas: não há.

Agradecimento/Contribuições adicionais: Os autores gostariam de agradecer o apoio da FAPEMIG, CAPES e CNPq.

Histórico do artigo: Submetido: 23.fev.2017 | Aceito: 10.ago.2017 | Publicado: 29.dez.2017

Apresentação anterior: não houve.

Licença CC BY-NC atribuição não comercial. Com essa licença é permitido acessar, baixar (download), copiar, imprimir, compartilhar, reutilizar e distribuir os artigos, desde que para uso não comercial e com a citação da fonte, conferindo os devidos créditos de autoria e menção à Reciis. Nesses casos, nenhuma permissão é necessária por parte dos autores ou dos editores. 


\section{Introdução}

A alimentação exerce um papel fundamental durante o ciclo de vida de um indivíduo, uma vez que ela é responsável pelas funções vitais dos mesmos. Conforme Ramos e Stein ${ }^{1}$, a alimentação é determinada por diversos fatores, como: fisiológicos, psicossociais, ambientais, familiares e outros.

Para o bom funcionamento do corpo essa alimentação deve ser saudável. O Guia Alimentar da População Brasileira apresenta uma definição bem fundamentada de alimentação saudável:

"A alimentação adequada e saudável é um direito humano básico que envolve a garantia ao acesso permanente e regular, de forma socialmente justa, a uma prática alimentar adequada aos aspectos biológicos e sociais do indivíduo e que deve estar em acordo com as necessidades alimentares especiais; ser referenciada pela cultura alimentar e pelas dimensões de gênero, raça e etnia; acessível do ponto de vista físico e financeiro; harmônica em quantidade e qualidade, atendendo aos princípios da variedade, equilíbrio, moderação e prazer; e baseada em práticas produtivas adequadas e sustentáveis²."

Segundo Amorim, Gontijo e Cardoso ${ }^{3}$, a alimentação saudável é o pilar para a saúde. Uma alimentação adequada e variada fornece os nutrientes necessários para a prevenção de doenças infecciosas, além de proteger contra a obesidade, diabetes, hipertensão arterial e alguns tipos de câncer. A prática de uma alimentação saudável se faz importante desde a infância, fase na qual os hábitos alimentares são formados. Assim, o ambiente familiar e escolar contribuem para o conhecimento de novos alimentos 4 .

Conforme o Conselho Federal de Nutricionistas do Brasil ${ }^{5}$, a alimentação escolar é toda a alimentação realizada pelo estudante durante o período em que se encontra na escola. Dessa forma, essa alimentação deve ser um mecanismo eficiente para ofertar, além de energia, os micronutrientes que são pouco disponibilizados na alimentação diária, não atingindo as recomendações necessárias dos alunos ${ }^{6}$.

No início da década de 1940, foi apresentada ao Governo Federal, pelo Instituto de Nutrição, uma proposta de oferta de alimentação escolar. Todavia, tal proposta não foi concretizada em virtude da falta de recursos financeiros. Entretanto, na década de 1950, um programa de alimentação escolar em âmbito nacional foi estruturado7. Em 1955, foi instituída a Campanha da Merenda Escolar (CME) em alguns estados brasileiros com o intuito de incentivar, proporcionar ou facilitar a alimentação do aluno, dando assistência técnica e financeira. No decorrer dos anos, seu nome e objetivos foram alterados, até que, em

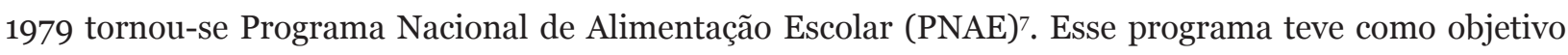
atender crianças matriculadas na pré-escola, ensino básico e fundamental, procurando suprir de $15 \%$ a $30 \%$ das necessidades nutricionais diárias dos alunos ${ }^{8}$.

O Programa Nacional de Alimentação Escolar passa por modificações desde a sua origem até os dias de hoje, principalmente em relação aos órgãos responsáveis, que antes eram autônomos ou da área de educação e saúde. Atualmente, o PNAE é uma responsabilidade do setor de educação, contudo a gestão se encontra centralizada no âmbito federal ${ }^{8}$.

Em 2006, foi exigida a presença de um nutricionista responsável pela elaboração do cardápio escolar nas Entidades Executoras. O objetivo era fornecer uma alimentação balanceada aos alunos, melhorando a qualidade do PNAE, uma vez que tal atividade era executada de forma improvisada pelas próprias merendeiras ${ }^{4}$. O nutricionista é responsável pela merenda escolar, elaboração do cardápio, processo de licitação dos gêneros alimentícios bem como o acompanhamento da produção da merenda nas escolas. Porém, na maioria das cidades, só existe um profissional para atender à todas as escolas do município ${ }^{5}$.

Para elaborar os cardápios, geralmente, o nutricionista necessita de muito tempo, visto que a qualidade, diversidade, preço e necessidades nutricionais devem ser considerados. Com o objetivo de facilitar o trabalho e contribuir para a redução de tempo na execução das atividades desse profissional, viu-se a 
utilidade de desenvolver um software aplicando alguma técnica computacional que auxiliasse na elaboração dos cardápios escolares, respeitando a faixa etária, necessidades nutricionais diárias dos alunos conforme a categoria: creche a EJA (Educação de Jovens e Adultos), localização (urbana, indígenas/quilombolas) e turnos de permanência na escola, tipo de alimentação (desjejum/colação, almoço/jantar e lanche), variedade, harmonia das preparações e custo da refeição.

O objetivo geral do planejamento de cardápios é alcançar refeições equilibradas e econômicas, de maneira a satisfazer um determinado conjunto de requisitos simultâneos para o qual foi proposto. Esse problema pretende encontrar a melhor combinação de itens que atendam aos objetivos e requisitos estipulados . $^{\circ}$

Nesse contexto, a aplicação de técnicas de Inteligência Artificial (IA) tornou-se um recurso promissor, sendo capaz de colaborar com diversos profissionais ao facilitar seu trabalho e contribuir para a redução de tempo na execução de suas atividades. A IA é um ramo da ciência que simula o comportamento humano e é subdividida em diversos campos, dentre eles a Computação Evolucionária. Essa, por sua vez, engloba vários algoritmos inspirados na evolução das espécies e na genética, por exemplo, Algoritmos Genéticos (AGs) ${ }^{10}$.

A proposta de solução apresentada neste trabalho considera dois aspectos fundamentais: reduzir o custo e, simultaneamente, atender às necessidades nutricionais diárias dos alunos. Propriedades desejáveis como: referência nutricional de acordo com a faixa etária fornecida pelo PNAE, variedade, harmonia das preparações culinárias e um limite de custo financeiro para cada tipo de refeição são inseridas no problema, como requisitos que devem ser respeitados. Por considerar dois aspectos, foi utilizada uma abordagem multiobjetivo para a resolução do problema.

\section{Aplicação de técnicas computacionais na elaboração de cardápios}

Desde 1964, técnicas assistidas por computadores, vem sendo utilizadas para resolver o problema de elaboração de cardápios. Balintfy ${ }^{9}$ utilizou técnicas de Programação Linear (PL) para construir o primeiro planejador de cardápios, com a finalidade de encontrar o custo mínimo e satisfazer as necessidades nutricionais diárias com um grau desejado de variedade, levando em consideração requisitos de cor e consistência para um número específico de dias.

Foi desenvolvido pelos Departamentos de Nutrição e Ciência da Computação da Universidade de Sonora no México um sistema de computador, PlaDiet ${ }^{11}$, que tem como objetivo calcular dietas individuais, cumprindo todos os requisitos nutricionais estabelecidos por um profissional. Para isso foi construído um modelo de programação inteira não linear, utilizando $\mathrm{AGs}^{10 .}$

Em 2012 outro software implementado foi o Pró-Dieta ${ }^{12}$, sistema que propõe a prescrição de cardápios e a formulação de dieta, no intuito de atender aos princípios de uma alimentação saudável, levando em consideração a variedade de cores e de refeição, a combinação de sabores, a textura e o fornecimento de todos os nutrientes. Seu público-alvo são pessoas de 18 a 65 anos.

\section{O CardNutri}

Diferentemente dos sistemas apresentados, o CardNutri foi desenvolvido com o intuito de auxiliar o nutricionista responsável pela elaboração de cardápios nutricionais escolares, contribuindo na redução do tempo que esse profissional despende com essa atividade.

Seu objetivo é elaborar cardápios coletivos minimizando o custo total e, simultaneamente, atendendo às necessidades nutricionais diárias dos alunos, respeitando a referência nutricional de acordo com a faixa etária fornecida pelo PNAE, variedade, harmonia das preparações culinárias e um limite de custo financeiro para cada tipo de refeição.

As preparações utilizadas no sistema foram divididas em: 1) acompanhamento: arroz e feijão; 2) entrada; 3) guarnição; 4) principal; 5) sobremesa: fruta ou outros; 6) bebida: suco ou outros; e 7) pão ou outros 
cereais. Para encontrar cardápios satisfatórios, o sistema utiliza métricas para comparar a qualidade de cada cardápio gerado. As métricas utilizadas são: 1) necessidades nutricionais, medida pelo erro nutricional, valor representado pela diferença entre a quantidade necessária de nutrientes e a quantidade de nutrientes do cardápio; e 2) valor monetário do cardápio elaborado. Todos os cardápios apresentados pelo sistema devem respeitar os princípios de harmonia (combinação de cores e consistência das preparações) e variedade.

Para validar o princípio da harmonia, quatro cores predominantes são definidas: amarelo, vermelho, verde e marrom para os tipos de preparações: entrada, guarnição, sobremesa e bebida, e dois tipos de consistência: líquido/pastoso e semissólido/sólido, conforme orientação de Gomes ${ }^{12}$. Nos cardápios elaborados pelo programa não são permitidas repetições de três ou mais cores. Em relação à consistência da preparação, não são permitidas repetições de líquido/pastoso para os tipos: acompanhamento feijão, guarnição e principal. A validação da variedade é realizada tanto para cada dia como em dias diferentes. Em um mesmo dia, para almoço e jantar, não são permitidas repetições dos seguintes tipos: entrada, guarnição, principal, sobremesa e bebida. Quando analisadas as refeições desjejum e lanche são verificados os seguintes tipos: fruta, bebida e cereal. Em dias diferentes, para almoço e jantar, não são permitidas repetições dos seguintes tipos: entrada, guarnição e principal.

Três bases de dados são utilizadas para a elaboração dos cardápios: ingredientes, preparações culinárias e referências nutricionais. A seguir será apresentada a estrutura de cada base e suas características:

- Ingredientes: itens das preparações culinárias. Para preencher essa base foi adotada a Tabela Brasileira de Composição de Alimentos - TACO, elaborada pelo Núcleo de Estudos e Pesquisas em Alimentação ${ }^{13}$. Ela é constituída por 597 alimentos, com valores nutricionais para cada 100 gramas. Como essa tabela não contém todos os ingredientes existentes, o programa aqui apresentado possibilita o cadastro de mais ingredientes. O PNAE recomenda que a aquisição de alguns gêneros alimentícios seja preferencialmente da Agricultura Familiar. No programa, os valores dos produtos pertencentes à Agricultura Familiar foram retirados da Tabela de Preços Praticados no PAA - Programa de Aquisição de Alimentos de Minas Gerais - Ano 2016, da Companhia Nacional de Abastecimento - $\mathrm{CONAB}^{14} \mathrm{e}$ os valores dos produtos que não se encontram nesta tabela foram retirados do Supermercado on-line VipFácil ${ }^{15}$.

- Características: Nome; Valor (R\$); Nutrientes: a) Energia (Kcal), b) Proteínas (g), c) Carboidratos (g), d) Lipídeos (g), e) Fibras (g), f) Minerais: Cálcio (mg), Ferro (mg), Zinco (mg) e Magnésio (mg); Grupo pertencente: 1. Cereais e derivados, 2. Verduras, Hortaliças e Derivados, 3. Frutas e Derivados, 4. Gorduras e Óleos, 5. Pescados e frutos do mar, 6. Carnes e derivados, 7. Leites e Derivados, 8. Bebidas, 9. Ovos e Derivados, 10. Produtos açucarados, 11. Miscelâneas, 12. Outros produtos industrializados, 13. Alimentos preparados, 14. Leguminosas e Derivados, 15. Nozes e sementes.

- Preparações Culinárias: preparações culinárias individuais compostas por ingredientes. As preparações culinárias foram retiradas da Cartilha "Cardápios da Alimentação Escolar" de Minas Gerais $^{16}$ e Goiás ${ }^{17}$.

- Características: Nome; Tipo: 1. Acompanhamento: a) Arroz, b) Feijão; 2. Entrada, 3. Guarnição, 4. Principal, 5. Sobremesa, 6. Bebida: a) Suco, b) Outro; 7. Pão/outros cereais; Cor: a) amarelo, b) vermelho, c) verde, d) marrom; Consistência: a) Líquido/pastoso, b) Semi-sólido/sólido; Ingredientes.

- Referências Nutricionais: As referências cadastradas foram retiradas da Resolução $n^{0}$ 26/20137 . A porcentagem das necessidades nutricionais diárias (NND) são: 20\% que equivale a uma refeição para escolas urbanas, 30\% que equivale a uma refeição para escolas indígenas ou quilombolas e $70 \%$ para turno integral.

- Características: Idade: a) 7 a 11 meses, b) 1 a 3 anos, c) 4 a 5 anos, d) 6 a 10 anos, e) 11 a 15 anos, f) 16 a 18 anos, g) 19 a 30 anos e h) 31 a 60 anos; Porcentagem: a) 20\%, b) 30\%, c) $70 \%$ e d) 100\%; Nutrientes: a) Energia (Kcal), b) Proteínas (g), c) Carboidratos (g), d) Lipídeos (g), e) Fibras (g), f) Minerais: Cálcio (mg), Ferro (mg), Zinco (mg) e Magnésio (mg). 
A seguir, as Tabelas 1, 2 e 3 mostram, respectivamente, os valores recomendados para 20\%, 30\% e 70\% das necessidades nutricionais diárias para pessoas de 7 meses a 60 anos. Nestas tabelas tem-se: CHO: carboidratos, PTN: proteínas e LIP: lipídeos.

Tabela 1. Valores de Referência de Energia, Macro e Micronutrientes - 20\% NND

\begin{tabular}{|c|c|c|c|c|c|c|c|c|c|c|c|c|}
\hline \multicolumn{13}{|c|}{$20 \%$ das necessidades nutricionais diárias } \\
\hline \multirow[b]{2}{*}{ Categoria } & \multirow[b]{2}{*}{ Idade } & \multirow{2}{*}{$\begin{array}{c}\text { Energia } \\
\text { (Kcal) }\end{array}$} & \multirow{2}{*}{$\frac{\mathrm{CHO}}{(\mathrm{g})}$} & \multirow{2}{*}{$\begin{array}{r}\text { PTN } \\
\text { (g) }\end{array}$} & \multirow{2}{*}{$\begin{array}{l}\text { LIP } \\
\text { (g) }\end{array}$} & \multirow{2}{*}{$\begin{array}{l}\text { Fibras } \\
(\mathrm{g})\end{array}$} & \multicolumn{2}{|c|}{ Vitaminas } & \multicolumn{4}{|c|}{ Minerais (mg) } \\
\hline & & & & & & & $\begin{array}{c}\text { A } \\
(\mu \mathrm{g})\end{array}$ & $\underset{(\mathrm{mg})}{\mathrm{C}}$ & $\mathrm{Ca}$ & $\mathrm{Fe}$ & $\mathrm{Mg}$ & $\mathrm{Zn}$ \\
\hline \multirow{2}{*}{ Creche } & $\begin{array}{l}7-11 \\
\text { meses }\end{array}$ & 135 & 21,9 & 4,2 & 3,4 & - & 100 & 10 & 54 & 2,2 & 15 & 0,6 \\
\hline & $\begin{array}{l}1-3 \\
\text { anos }\end{array}$ & 200 & 32,5 & 6,3 & 5 & 3,8 & 60 & 3 & 100 & 1,4 & 16 & 0,6 \\
\hline Pré-escola & $\begin{array}{l}4-5 \\
\text { anos } \\
\end{array}$ & 270 & 43,9 & 8,4 & 6,8 & 5 & 80 & 5 & 160 & 2 & 26 & 1 \\
\hline Ensino & $\begin{array}{l}6-10 \\
\text { anos }\end{array}$ & 300 & 48,8 & 9,4 & 7,5 & 5,4 & 100 & 7 & 210 & 1,8 & 37 & 1,3 \\
\hline Fundamental & $\begin{array}{c}11-15 \\
\text { anos }\end{array}$ & 435 & 70,7 & 13,6 & 10,9 & 6,1 & 140 & 12 & 260 & 2,1 & 63 & 1,8 \\
\hline Ensino Médio & $\begin{array}{c}16-18 \\
\text { anos }\end{array}$ & 500 & 81,3 & 15,6 & 12,5 & 6,4 & 160 & 14 & 260 & 2,6 & 77 & 2 \\
\hline \multirow{2}{*}{ EJA } & $\begin{array}{c}19-30 \\
\text { anos }\end{array}$ & 450 & 73,1 & 14 & 11,3 & 6,3 & 160 & 17 & 200 & 2,6 & 71 & 1,9 \\
\hline & $\begin{array}{c}31-60 \\
\text { anos }\end{array}$ & 435 & 70,7 & 13,6 & 10,9 & 5,7 & 160 & 17 & 220 & 2,1 & 74 & 1,9 \\
\hline
\end{tabular}

Fonte: Adaptada de Energia - Organização das Nações Unidas para Agricultura e Alimentação (FAO), 2001; Carboidrato, Proteína e Lipídio - Organização Mundial de Saúde (OMS), 2003; Fibras, Vitaminas e Minerais - Referência da Ingestão Dietética (DRI) / Instituto de Medicina Americano (IOM), 1997 - 2000 - 2001.

Tabela 2. Valores de Referência de Energia, Macro e Micronutrientes - 30\% NND

\begin{tabular}{|c|c|c|c|c|c|c|c|c|c|c|c|c|}
\hline \multicolumn{13}{|c|}{$30 \%$ das necessidades nutricionais diárias } \\
\hline \multirow[b]{2}{*}{ Categoria } & \multirow[b]{2}{*}{ Idade } & \multirow{2}{*}{$\begin{array}{l}\text { Energia } \\
(\text { Kcal }) \\
\end{array}$} & \multirow{2}{*}{$\begin{array}{c}\mathrm{CHO} \\
(\mathrm{g}) \\
\end{array}$} & \multirow{2}{*}{$\begin{array}{c}\text { PTN } \\
(\mathrm{g}) \\
\end{array}$} & \multirow{2}{*}{$\begin{array}{l}\text { LIP } \\
(\mathrm{g}) \\
\end{array}$} & \multirow{2}{*}{$\begin{array}{c}\text { Fibras } \\
\text { (g) } \\
\end{array}$} & \multicolumn{2}{|c|}{ Vitaminas } & \multicolumn{4}{|c|}{ Minerais (mg) } \\
\hline & & & & & & & $\begin{array}{c}\text { A } \\
(\mu g)\end{array}$ & $\begin{array}{c}\mathrm{C} \\
(\mathrm{mg})\end{array}$ & $\mathrm{Ca}$ & $\mathrm{Fe}$ & $\mathrm{Mg}$ & $\mathrm{Zn}$ \\
\hline \multirow[t]{2}{*}{ Creche } & $\begin{array}{l}\text { 7- } 11 \text { me- } \\
\text { ses }\end{array}$ & 200 & 32,5 & 6,3 & 5 & - & 150 & 15 & 81 & 3,3 & 23 & 0,9 \\
\hline & $1-3$ anos & 300 & 48,8 & 9,4 & 7,5 & 5,7 & 90 & 5 & 150 & 2,1 & 24 & 0,9 \\
\hline Pré-escola & $4-5$ anos & 400 & 65 & 12,5 & 10 & 7,5 & 120 & 8 & 240 & 3 & 39 & 1,5 \\
\hline Ensino & $\begin{array}{l}6-10 \\
\text { anos }\end{array}$ & 450 & 73,1 & 14 & 11,3 & 8 & 150 & 11 & 315 & 2,7 & 56 & 2 \\
\hline Fundamental & $\begin{array}{c}11-15 \\
\text { anos }\end{array}$ & 650 & 105,6 & 20,3 & 16,3 & 9 & 210 & 18 & 390 & 3,2 & 95 & 2,7 \\
\hline Ensino Médio & $\begin{array}{c}16-18 \\
\text { anos }\end{array}$ & 750 & 121,8 & 23,4 & 18,8 & 9,6 & 240 & 21 & 390 & 3,9 & 116 & 3 \\
\hline \multirow{2}{*}{ EJA } & $\begin{array}{c}19-30 \\
\text { anos }\end{array}$ & 680 & 110,5 & 21,3 & 17 & 9,5 & 240 & 26 & 300 & 3,9 & 107 & 2,9 \\
\hline & $\begin{array}{c}31-60 \\
\text { anos }\end{array}$ & 650 & 105,6 & 20,3 & 16,3 & 8,5 & 240 & 26 & 330 & 3,2 & 111 & 2,9 \\
\hline
\end{tabular}

Fonte: Adaptada de Energia - FAO, 2001; Carboidrato, Proteína e Lipídio - OMS, 2003; Fibras, Vitaminas e Minerais - DRI / IOM, 1997 - 2000 - 2001. 
Tabela 3. Valores de Referência de Energia, Macro e Micronutrientes - 70\% NND

\begin{tabular}{|c|c|c|c|c|c|c|c|c|c|c|c|c|}
\hline \multicolumn{13}{|c|}{$70 \%$ das necessidades nutricionais diárias } \\
\hline \multirow[b]{2}{*}{ Categoria } & \multirow[b]{2}{*}{ Idade } & \multirow{2}{*}{$\begin{array}{l}\text { Energia } \\
\text { (Kcal) } \\
\end{array}$} & \multirow{2}{*}{$\begin{array}{l}\mathrm{CHO} \\
(\mathrm{g})\end{array}$} & \multirow{2}{*}{\begin{tabular}{|l} 
PTN \\
(g) \\
\end{tabular}} & \multirow{2}{*}{$\begin{array}{l}\text { LIP } \\
\text { (g) }\end{array}$} & \multirow{2}{*}{$\begin{array}{l}\text { Fibras } \\
\text { (g) }\end{array}$} & \multicolumn{2}{|c|}{ Vitaminas } & \multicolumn{4}{|c|}{ Minerais $(\mathrm{mg})$} \\
\hline & & & & & & & $\begin{array}{l}\text { A } \\
(\mu g)\end{array}$ & $\begin{array}{l}\mathrm{C} \\
(\mathrm{mg})\end{array}$ & $\mathrm{Ca}$ & $\mathrm{Fe}$ & $\mathrm{Mg}$ & $\mathrm{Zn}$ \\
\hline \multirow[t]{2}{*}{ Creche } & $\begin{array}{l}7-11 \\
\text { meses }\end{array}$ & 450 & 73,1 & 14 & 11,3 & - & 350 & 35 & 189 & 7,7 & 54 & 2,1 \\
\hline & $1-3$ anos & 700 & 114,9 & 21,9 & 17,5 & 13,3 & 210 & 12 & 350 & 4,9 & 56 & 2,1 \\
\hline Pré-escola & $4-5$ anos & 950 & 154,4 & 29,7 & 23,8 & 17,5 & 280 & 19 & 560 & 7 & 91 & 3,5 \\
\hline Ensino & $\begin{array}{l}6-10 \\
\text { anos }\end{array}$ & 1000 & 162,5 & 31,2 & 25 & 18,7 & 350 & 26 & 735 & 6,3 & 131 & 4,7 \\
\hline Fundamental & $\begin{array}{l}11-15 \\
\text { anos }\end{array}$ & 1500 & 243,8 & 46,9 & 37,5 & 21,1 & 490 & 42 & 910 & 7,5 & 222 & 6,3 \\
\hline Ensino Médio & $\begin{array}{l}16-18 \\
\text { anos }\end{array}$ & 1700 & 276,3 & 50 & 42,5 & 22,4 & 560 & 49 & 910 & 9,1 & 271 & 7 \\
\hline \multirow{2}{*}{ EJA } & $\begin{array}{l}19-30 \\
\text { anos }\end{array}$ & 1600 & 260 & 52 & 40 & 22,1 & 560 & 61 & 700 & 9,1 & 250 & 6,8 \\
\hline & $\begin{array}{l}31-60 \\
\text { anos }\end{array}$ & 1500 & 243,8 & 46,9 & 37,5 & 20 & 560 & 61 & 770 & 7,5 & 259 & 6,8 \\
\hline
\end{tabular}

Fonte: Adaptada de Energia - FAO, 2001; Carboidrato, Proteína e Lipídio - OMS, 2003; Fibras, Vitaminas e Minerais -DRI / IOM, $1997-2000-2001$.

A técnica escolhida para elaborar automaticamente os cardápios foi a utilização de Algoritmos Genéticos. Goldberg ${ }^{18}$ os define como uma técnica de busca baseada no processo de evolução biológica e à medida que o processo evolui, melhores soluções são obtidas. O seu funcionamento é dado por gerar uma população de indivíduos que evoluem de forma semelhante à evolução das espécies. Cada indivíduo recebe uma avaliação que é um valor referente à sua qualidade como solução do problema em questão, e baseado nesta avaliação, são aplicados os operadores genéticos: recombinação, mutação e seleção de forma a simular a sobrevivência do indivíduo mais apto.

Neste artigo deseja-se minimizar o custo e o erro nutricional, logo, temos dois objetivos a serem atingidos simultaneamente. Geralmente, esses objetivos são conflitantes, quanto maior o valor de um, menor o valor do outro e vice-versa. Portanto, uma abordagem multiobjetivo foi aplicada. Maiores detalhes do funcionamento e da implementação de um Algoritmo Genético para o problema de elaboração de cardápios, podem ser obtidos no artigo de Moreira, Martins e Wanner ${ }^{19}$.

As soluções de uma abordagem multiobjetivo, ou soluções Pareto, são as melhores soluções dentre as quais não é possível definir qual é a melhor, pois são incomparáveis, uma vez que todas satisfazem, ao mesmo tempo, os dois objetivos. A Figura 1 ilustra um conjunto de soluções, onde os pontos A, B, C, D, E e F são soluções do Pareto. O ponto G caracteriza uma solução ruim, pois existem soluções no Pareto que são melhores, isso significa que as soluções C, D e E dominam a solução G. Cada ponto desse gráfico representa um cardápio, lembrando que deseja-se minimizar o preço e o erro nutricional. Analisando o cardápio D (preço $=\mathrm{R} \$ 28,00$ e erro = 3000) e o cardápio $\mathrm{G}($ preço $=\mathrm{R} \$ 28,70$ e erro $=3700)$, o preço e o erro de D são menores que o de G. Portanto, o cardápio D é melhor que o G sendo esse descartado. Outra possível análise é a comparação entre o cardápio $\mathrm{C}$ (preço $=\mathrm{R} \$ 28,50$ e erro $=2500$ ) e o cardápio $\mathrm{D}$ (preço $=\mathrm{R} \$ 28,00$ e erro = 3000), em que não é possível definir qual deles é melhor, pois o preço de $\mathrm{D}$ é menor, mas o erro é maior. O conjunto de soluções como essas, que não possuem uma ordenação, é conhecido como Pareto. Então, necessita-se de um decisor para escolher a solução que melhor lhe atender conforme as suas condições. 


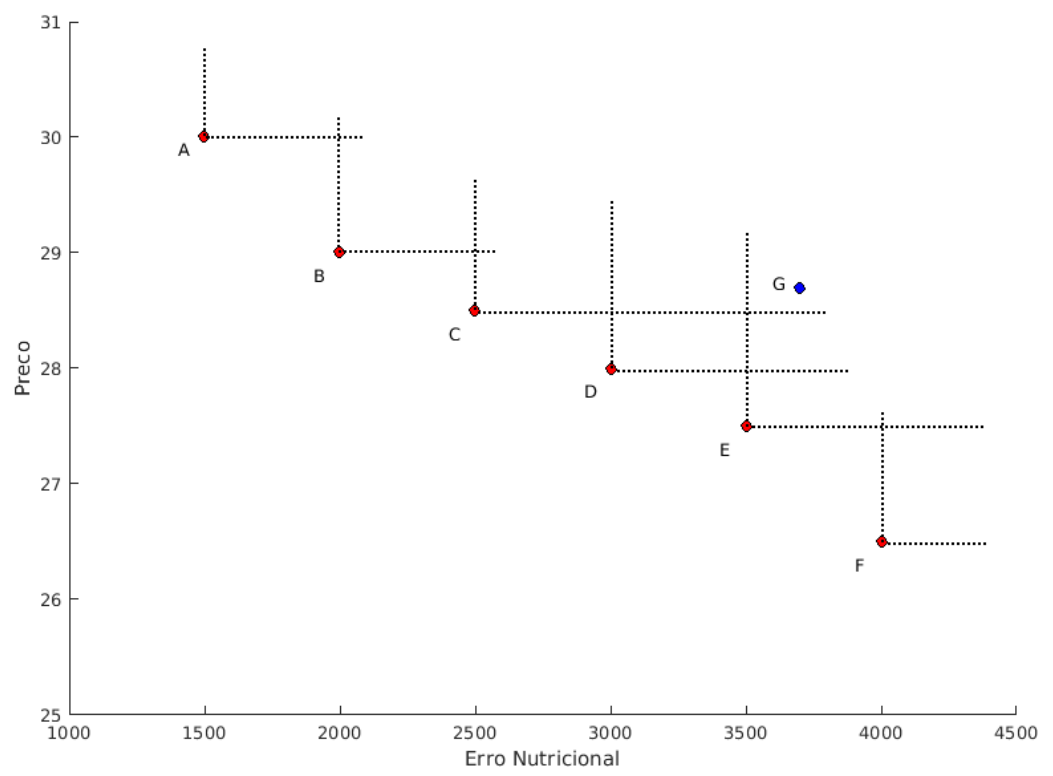

Figura 1. Exemplo de dominância de soluções

Fonte: Os autores (2017)

Para gerar o cardápio é necessário informar: os tipos de refeições: 1) Desjejum: composto por uma fruta, uma bebida (leite ou derivados) e um pão (ou outros cereais); 2) Almoço/jantar: a) Acompanhamento: arroz e feijão, b) Entrada: salada, c) Guarnição: vegetal ou massa, d) Principal: carne, e) Sobremesa: doce ou fruta, f) Bebida: suco ou leite e derivados; 3) Lanche: tem as mesmas atribuições do desjejum, porém na bebida também é aceito o suco; valor máximo para cada tipo de refeição; a referência nutricional a ser atingida; quantidade de dias. Posteriormente, são apresentados todos os cardápios fornecidos e suas características. O sistema possibilita salvar esses cardápios no banco de dados, além de exportar em formato PDF.

Quando existem cardápios salvos é possível consultá-los, bem como as refeições. O sistema também permite a emissão completa de relatórios de ingredientes, preparações culinárias, referências nutricionais, refeições e cardápios.

\section{Linguagens e ferramentas utilizadas}

Para o desenvolvimento do sistema foram utilizadas as seguintes ferramentas:

- Java: linguagem de programação interpretada orientada a objetos que possui um conjunto extenso de bibliotecas (API's - Application Program Interface).

- NetBeans: ambiente de desenvolvimento integrado gratuito para desenvolvimento de software em diversas linguagens, por exemplo, Java.

- API Swing: biblioteca gráfica responsável pelas interfaces gráficas do sistema, ela desenha todos os componentes necessários.

- MySQL: sistema de gerenciador de banco de dados que utiliza a linguagem SQL (Structured Query Language), é compatível com diversas linguagens de programação e é de fácil utilização.

- JFreeChart: biblioteca de gráficos que suporta formatos como: PDF, EPS, PNG, JPEG e outros. 


\section{Interação com o sistema}

A interface do sistema foi projetada para ser simples e de fácil compreensão. A Figura 2 ilustra a tela inicial do sistema com um menu superior. Este menu permite:

- Cadastrar, alterar e excluir: ingredientes, preparações culinárias e referências nutricionais;

- Gerar cardápio;

- Consultar refeições e cardápios;

- Gerar relatórios (formato PDF): ingredientes, preparações culinárias, referências nutricionais, refeições e cardápios;

- Visualizar informações do sistema;

- Sair.

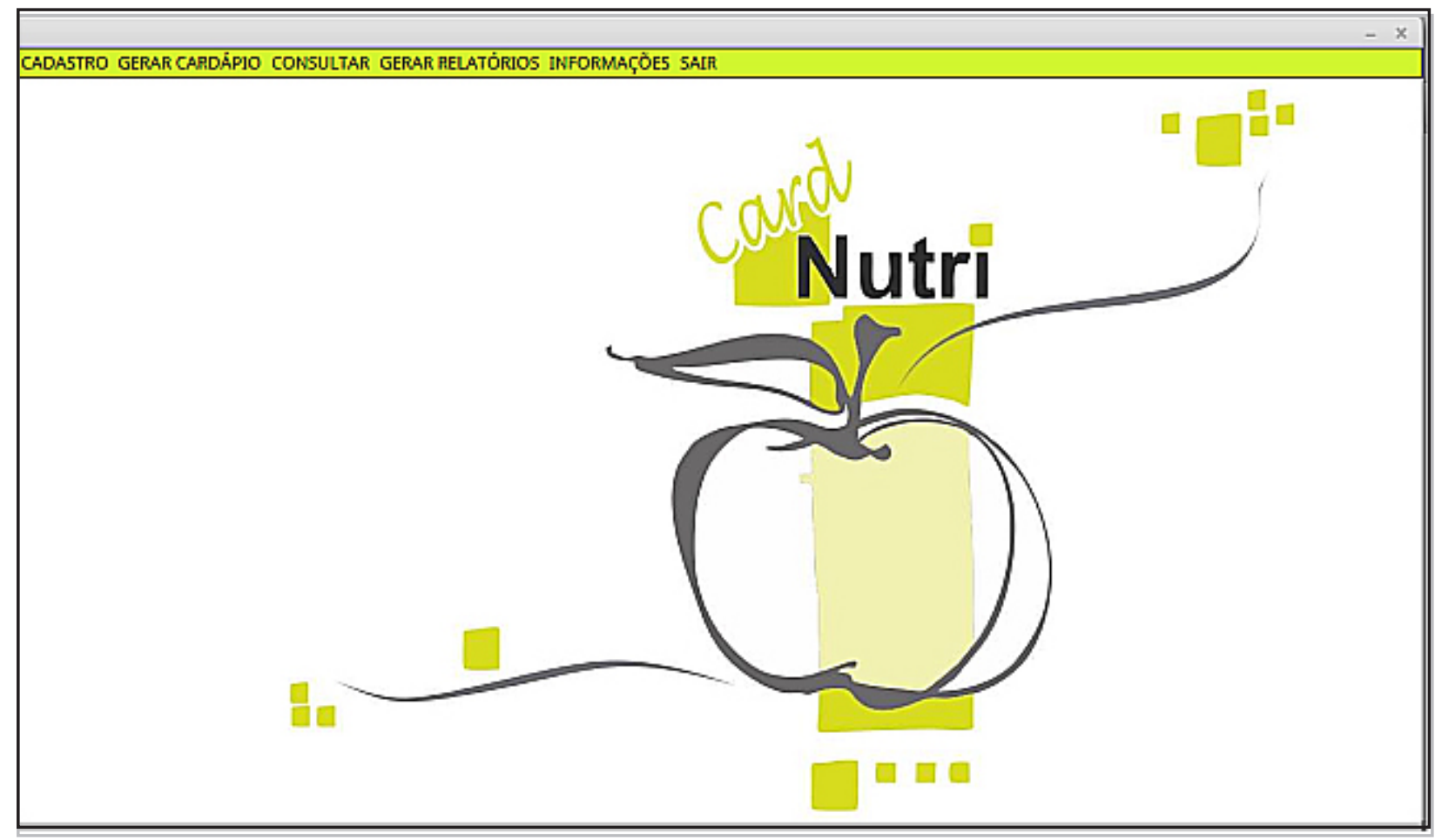

Figura 2. Tela inicial

A Figura 3 mostra as telas de cadastro, alteração e exclusão de ingredientes, preparações culinárias e referências nutricionais. Através do botão "Pesquisar" é possível consultar todos os itens cadastrados.

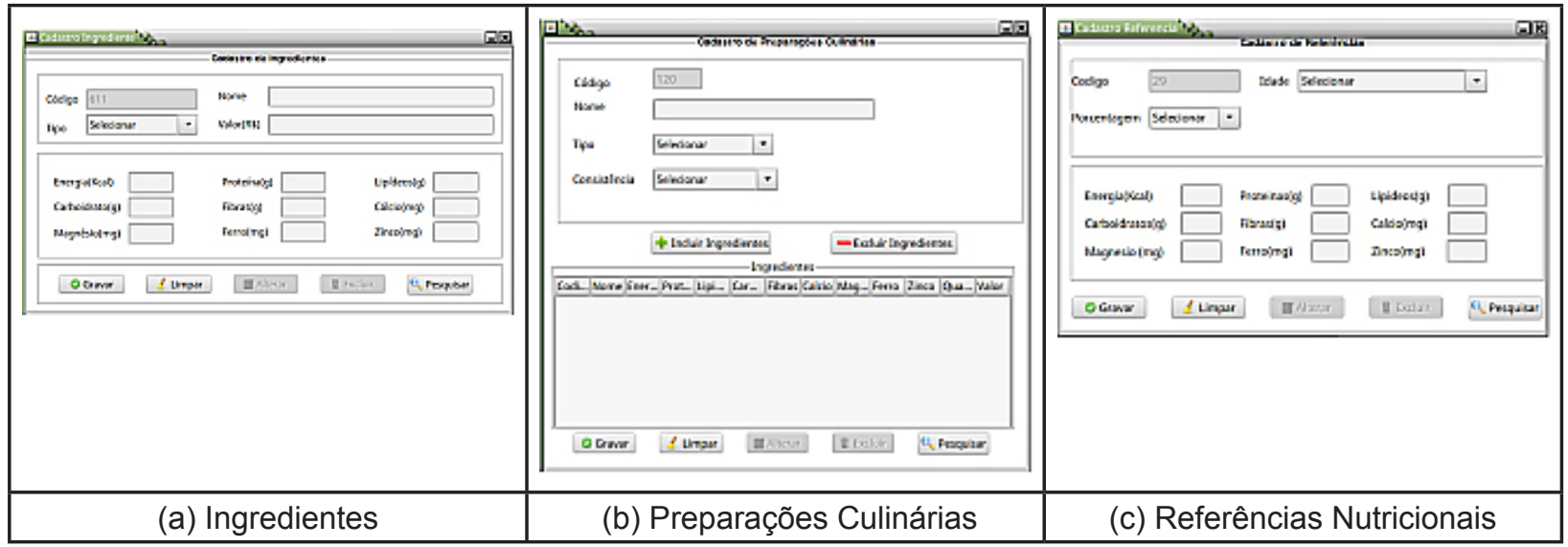

Figura 3. Telas de cadastro, alteração e exclusão de ingredientes, preparações culinárias e referências nutricionais 
A Figura 4 ilustra a tela de gerar cardápio. É necessário definir quais os tipos de refeições e o valor máximo a ser pago por cada um desses tipos, a referência nutricional a ser atingida e o número de dias, correspondendo a um cardápio semanal. O botão "Avançado" corresponde às configurações essenciais da técnica utilizada, porém não é obrigatório o seu preenchimento, uma vez que essas configurações já estão definidas.

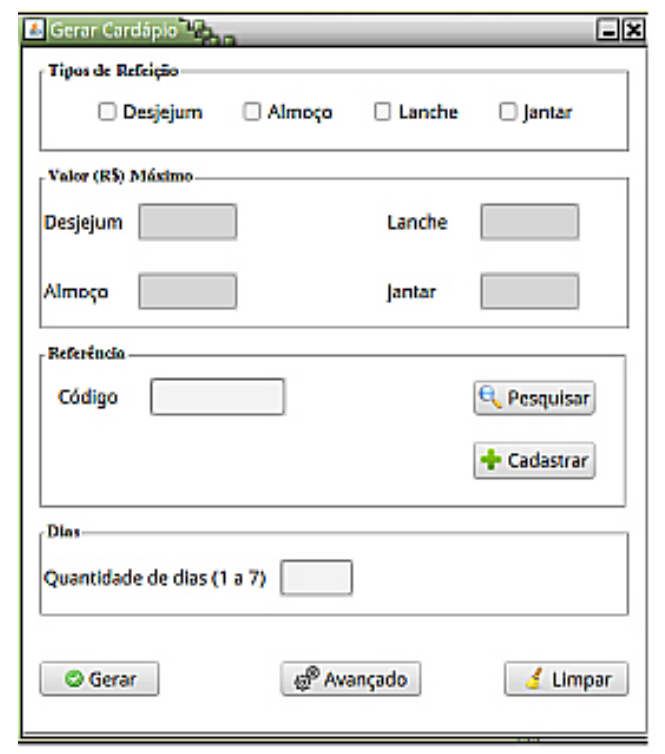

Figura 4. Tela de geração do cardápio

A Figura 5 ilustra a tela dos cardápios elaborados pelo sistema. Nesta tela é possível ver a quantidade de cardápios gerados, sua composição, valor e erro nutricional. O gráfico mostra a curva Pareto dos cardápios encontrados, facilitando a escolha do nutricionista. Ao clicar em um ponto do gráfico, suas informações são preenchidas na tela. O menu "Arquivo", permite salvar o cardápio atual ou todos os cardápios no banco de dados, possibilitando assim, sua consulta posteriormente e exportar em PDF o cardápio atual ou todos os cardápios.

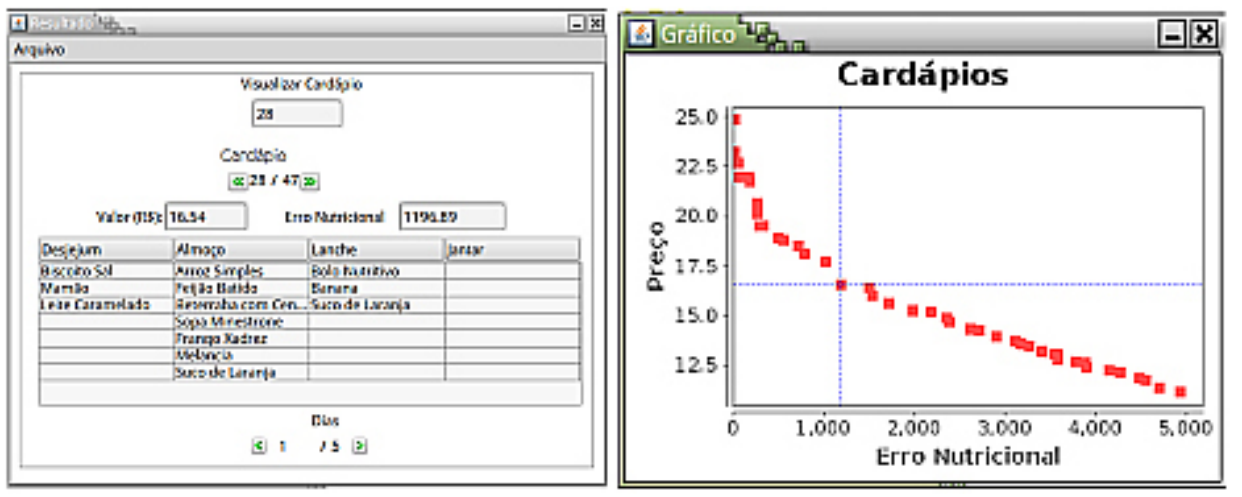

Figura 5. Tela dos cardápios elaborados. É possível escolher na curva Pareto a solução desejada

\section{Resultados e discussões}

Para verificar a aceitação do CardNutri por nutricionistas, foi realizado um questionário baseado no Modelo de Aceitação de Tecnologia (Technology Acceptance Model - TAM) proposto por Davis ${ }^{20}$. Os participantes tiveram que utilizar o sistema realizando uma lista de tarefas que foi elaborada com a finalidade de ajudar a responder o questionário. O questionário contém vinte afirmativas positivas agrupadas em cinco categorias: Facilidade Percebida refere-se ao grau que um usuário acredita que utilizar o sistema não envolverá esforço; Utilidade Percebida refere-se ao grau que um usuário acredita que utilizar o sistema irá melhorar a sua performance; Variáveis Externas referem-se às características do sistema e treinamento; 
Atitude em Relação diz respeito ao sentimento do usuário de estar favorável ou não em relação ao uso do sistema; e Intenção Comportamental de Uso refere-se à força da intenção de usar o sistema no futuro. O questionário foi respondido por nove nutricionistas com experiência em alimentação escolar ou coletiva.

O questionário utiliza a escala Likert ${ }^{21}$ de cinco pontos, que é um tipo de escala psicométrica, onde o usuário especifica o nível de concordância ou discordância, a partir de uma afirmação. Cada ponto da escala é representado por um valor que se encontra entre parênteses. Como as afirmações são positivas, o ponto "concordo plenamente" tem o maior valor. Os níveis empregados foram: discordo plenamente (1), discordo parcialmente (2), nem concordo nem discordo (3), concordo parcialmente (4), concordo plenamente (5).

Outra técnica utilizada foi a Thinking Aloud ${ }^{22}$, estratégia de pensar em voz alta. Os participantes expressam suas opiniões e sugestões durante a avaliação ou enquanto executam alguma tarefa ${ }^{20}$.

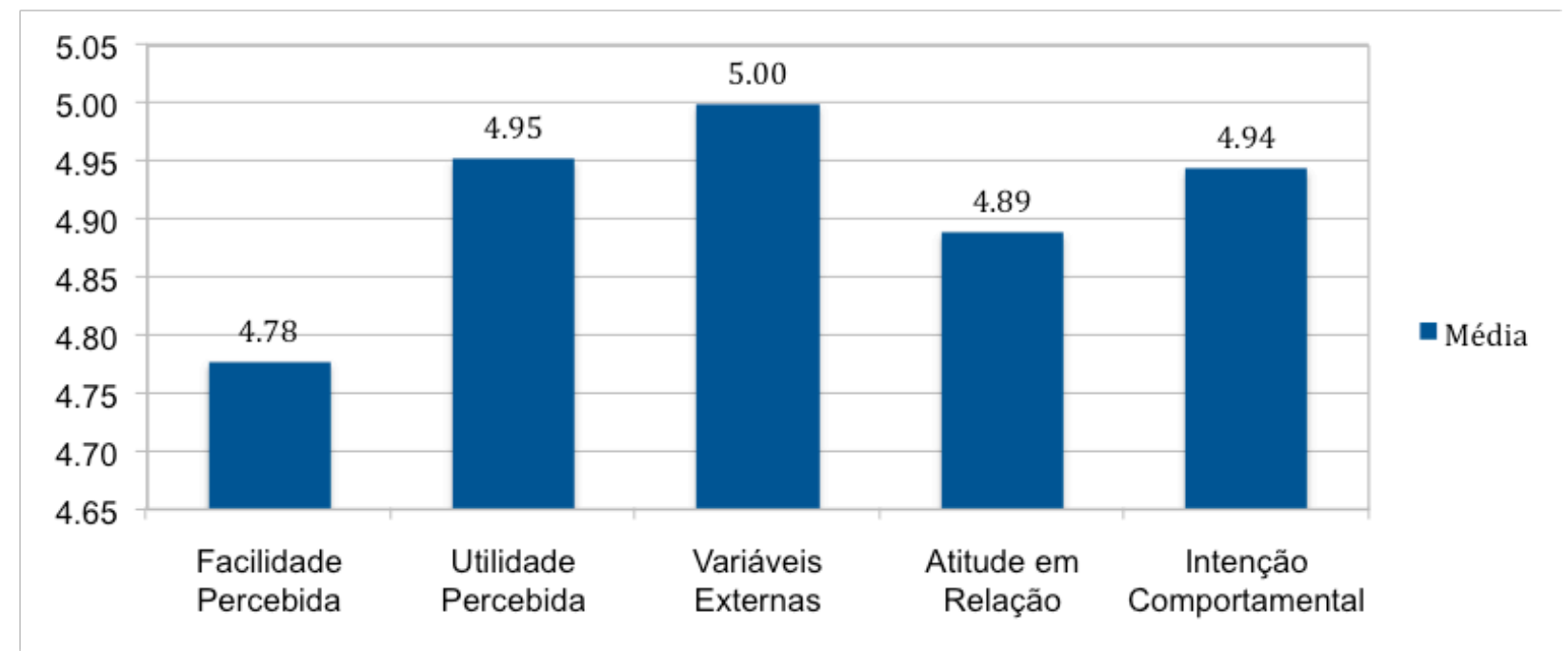

Figura 6. Médias das categorias do questionário de avaliação

A Figura 6 ilustra as médias para cada categoria avaliada. No gráfico apresentado nessa figura é possível perceber que a Facilidade Percebida teve a menor média $(4,78)$, pois dentre as questões dessa categoria, algumas das participantes acreditam que há certo esforço mental na interação com o sistema, principalmente no início, mas que ele é fácil de usar. Com relação a Utilidade Percebida (média $=4,95$ ) o sistema adiciona valor ao trabalho das participantes, aumentando sua performance, eficiência e produtividade. Quanto às Variáveis Externas (média = 5,0), elas concordaram que teve um bom treinamento e a explicação foi clara. Em relação à Atitude em Relação (média $=4,89$ ), seria muito bom utilizar o sistema no lugar do método atual que é manual. E por fim, sobre a Intenção Comportamental (média $=4,94$ ), caso tenham acesso ao sistema, elas pretendem usá-lo.

Através da técnica Thinking Aloud, todos concordaram que o sistema atingiu ao objetivo proposto que é elaborar, automaticamente, cardápios nutritivos e baratos e sugeriram que o sistema deveria ter a opção de alterar uma preparação após a elaboração do cardápio, apresentar o valor nutricional de cada cardápio nos relatórios, acrescentar medidas caseiras, receitas e outras tabelas nutricionais de referência e calcular o valor da Energia (kcal) através dos macronutrientes.

\section{Considerações finais}

Este artigo apresentou o sistema de Elaboração de Cardápios Nutricionais para a Alimentação Escolar CardNutri ${ }^{23}$, desenvolvido para auxiliar nutricionistas na elaboração de cardápios. Os resultados mostraram que a utilização desse sistema na Alimentação Escolar é uma boa alternativa para atender algumas exigências do PNAE que é uma alimentação saudável, respeitando as referências nutricionais conforme a faixa etária, 
localização da escola, período de permanência do aluno na escola, harmonia e variedade das preparações e baixo custo, além de facilitar e agilizar o trabalho das nutricionistas que necessitam de tempo para executar outras atividades de sua responsabilidade.

Uma dificuldade percebida durante a execução das tarefas foi no momento da alteração de ingredientes, preparações culinárias e referências nutricionais, no qual deve-se clicar no botão "Pesquisar" para que tal tarefa seja realizada, mas a maioria das participantes tentaram digitar o nome sem pesquisar. Como foi algo comum entre muitas, uma alternativa seria permitir a pesquisa pelo nome já na tela de cadastro, sem precisar clicar no botão "Pesquisar".

Como trabalhos futuros, pretende-se fazer as alterações plausíveis sugeridas pelas nutricionistas e alterar a forma de pesquisa para facilitar ainda mais a interação com o sistema. Além disso, pretende-se melhorar ainda mais as soluções fornecidas pela técnica de inteligência artificial empregada.

\section{Referências}

1. Ramos M, Stein LM. Desenvolvimento do comportamento alimentar infantil. J Pediatr. 2000;76(3).

2. Ministério da Saúde (BR). Guia alimentar para a população brasileira. 2 ed. Brasília (DF); 2014.

3. Amorim ESD, Almeida NF, Gontijo T, Cardoso GT. Cardápios saudáveis. Brasília (DF); 2009.

4. Mascarenhas JMO, Santos JC. Avaliação da composição nutricional dos cardápios e custos da alimentação escolar da rede municipal de conceição do jacuípe. Sitientibus: R Univ Est. 2006 jul./ dez.;(35):75-90.

5. Conselho Federal de Nutricionistas (BR). Resolução CFN no 380, de 9 de dezembro de 2005. Dispõe sobre a definição das áreas de atuação do nutricionista e suas atribuições, estabelece parâmetros numéricos de referência, por área de atuação, e dá outras providências. Brasília (DF): Diário Oficial da União; 2005:66-71.

6. Stefanini MLR. Merenda escolar: história, evolução e contribuição no atendimento das necessidades nutricionais da criança [dissertação]. São Paulo: Universidade de São Paulo, Faculdade de Saúde Pública; 1997.

7. Ministério da Educação (BR). Fundo Nacional de Desenvolvimento da Educação. Resolução n 26, de 17 de junho de 2013. Dispõe sobre o atendimento da alimentação escolar aos alunos da educação básica no âmbito do Programa Nacional de Alimentação Escolar - PNAE. Diário Oficial da República Federativa do Brasil, DF, 18 jun. 2013 [citado 2015 dez. 20]; Seção 1. Disponível em: https://goo.gl/eUWfR]

8. Spinelli MAS. O programa de alimentação escolar no estado de Mato Grosso: da concentração à descentralização (1979-1995). R Nutr. 2002 jan./abr.;15(1):105-17.

9. Balintfy J. Menu planning by computer. Comunic ACM. 1964 Apr;7(4):255-9.

10. Holland JH. Adaptation in natural and artificial systems. Cambridge: Massachusetts; 1975.

11. Flores P, Cota MG, Ramírez D, Jiménez IJ, Raygoza JA, Morales LC et al. Pladiet: un sistema de cómputo para el diseño de dietas individualizas utilizando algoritmos genéticos. RISCI. 2006;3(2):23-7.

12. Gomes FR. Pró-dieta: gerador automático de cardápios personalizados baseado em algoritmo genético [dissertação]. Uberlândia: Universidade Federal de Uberlândia, Faculdade de Engenharia Elétrica; 2012.

13. Núcleo de Estudos e Pesquisas em Alimentação, Universidade Estadual de Campinas. Tabela brasileira de composição de alimentos - TACO. 4 rev. ampli. São Paulo; 2011.

14. Companhia Nacional de Abastecimento (BR). Tabela de Preços Praticados no PAA - Programa de Aquisição de Alimentos de Minas Gerais, 2016.

15. VipFacil supermercado. Belo Horizonte; [2000] [citado 2016 mar. 17]. Disponível em: https://www. vipfacil.com.br/

16. Secretaria de Estado de Educação (MG). Cardápios de alimentação escolar: educação básica. Belo Horizonte; 2014.

17. Secretaria de Estado de Educação (GO). Cardápios de alimentação escolar. Goiás; 2014. 
18. Goldberg DE. Genetic algorithms in search, optimization and machine learning. New Yok: Addison Wesley Publishing Co., 1989.

19. Moreira RPC, Martins FVC, Wanner EF. Algoritmo genético para elaboração de cardápios nutricionais para alimentação escolar. Anais do $12^{\circ}$ Congresso Brasileiro de Inteligência Computacional; 2015. [citado 2017 fev. 23]. Disponível em: http://abricom.org.br/wp-content/uploads/2016/01/cbic2015 submission 140.pdf

20. Davis FD. Perceived usefulness, perceived ease of use, and user acceptance of information technology. MIS Quarterly. 1989 Sep;13(3):319-40.

21. Likert R. A technique for the measurement of attitudes. New York: The Science Press, 1932. P. 1-55 (Archives of Psychology, 140).

22. Lewis $\mathrm{CH}$. Using the "thinking aloud" method in cognitive interface design. Yorktown Heights, NY: IBM T.J. Watson Research Center; 1982.

23. Moreira RPC, Martins FVC, Wanner EF, inventores. Centro Federal de Educação Tecnológica de Minas Gerais, Fundação de Amparo à Pesquisa do Estado de Minas Gerais, titulares. CardNutri: sistema de elaboração de cardápios nutricionais para a alimentação escolar. BR 512016 000660-9. 2016 out. 04 [citado 2017 fev. 23]. Disponível em: https://goo.gl/JFgncQ 